\title{
ETNICIDAD Y SOCIEDAD EN EL MACIZO COLOMBIANO
}

\author{
A la memoria de Jorge Alherto Hormiga Mejía, \\ fallecido en 1 de Enero de 1993; \\ compañero sin par en la primera etapa del proyecto.
}

Carlos Vladimir Zambrano

* Instivito Colombiano de Antropología 
Desde 1991, el Instituto Colombiano de Antropología, con el apoyo del Plan Nacional de Rehabilitación conformó el programa de Historia Local y Regional', del cual el proyecto Etnicidad y Sociedad enel Macizo Colombiano formó parte. La actividad se inició con cuatro proyectos nucvos ${ }^{2}$, que sc situaron en las zonas de influencia PNR, pero sobre todo en las que permiticran estudiar la forma como se presentan los conflictos desde hace 50 años y los mecanismos que las comunidades usan para resolverlos sin llegar a la violencia.

El proyecto Etnicidad y Sociedad en el Macizo Colombiano, buscaba no sólo lograr los objetivos del PNR en la zona, sino que buscó impulsar a la par, investigaciones precisas de corte etnológico que atendicran una región, que según Kathleen Romoli (1962:62), "ha permanecido poco menos que un blanco en el cuadro del descubrimiento y colonización de Colombia". Era preciso hacerlo si se pretendía investigar sobre hechos más recientes en clla. Lo era porque al concebirse en todo el país el Macizo Colombiano como un reservorio de aguas, la estrella fluvial, el hombre que lo habita se había convertido en poco menos que una abstracción. Allí no hahía cultura, sino páramos.

Por ello el interrogante, de la década de los 30 (quiénes eran y de dónde venían las raíces de los actuales pobladores de la región?) estaba vigente y precisaba una respuesta (Cfr. Friede: 1944: 6).

1. La coordinación del programa la ha realizado Rita Combariza del Plan Nacional de Rehabilitación, quien ha estado al tanto del desarrollo del programa desde su inicio. Desde 1992, Eduardo Ariza, por parte del Instituto Colombiano de Antropología, há compartido con ella la coordinación.

2. Historias de desierto y de montaña en Huila; Historias del Río Minero, en Boyacá; l as Provincias de Pamplona y Ocaña, en Norte de Santander; y, Einicidad y Suciedad en el Macizo Colombiano, en Cauca. 
Con la publicación de Hombres de páramo y montaña. Los Yanacona del Macizo Colombiano (Zambrano:1993), se intentó resolver en parte este interrogante desde una perspectiva etnológica, que junto con la monografía, Yanaconas, para la Enciclopedia Indigenas de Colombia, del Instituto de Cultura Hispánica, tomo del suroccidente, constituyen el primer aporte sistemático al conocimiento etnológico en el área ${ }^{3}$.

Dejando de lado la preocupación etnológica, de todas maneras fuente del desarrollo subsecuente de la investigación, el objeto del proyecto se enmarca dentro de la problemática entendida como el conflicto etnia-región-nación, en el ámbito de los estudios andinos, y emplea un enfoque etnográfico comparativo. Su propósito ha sido fortalecer a las comunidades yanaconas de la región: San Sebastián, Guachicono, Caquiona, Pancitará, Rioblanco, Frontino, El Moral y El Oso, en lo relativo al territorio, y al gobierno interno y a la autonomía, a la vez que ha fomentado el reconocimiento del Pueblo Yanacona.

El objetivo de Etnicidad y Sociedad en el Macizo Colombiano, es aportar al conocimiento de la región a través del estudio de las expresiones de la relación conflicto-identidad-sociedad. En consecuencia, se trata de examinar de manera detallada el proceso por el cual se desarrolla la identidad a partir de los conflictos, sean estos impulsados desde sectores locales, regionales e incluso nacionales; conflictos que, no está por demás decirlo, no son de exclusivo orden cultural. La etnicidad se manifiesta a través de distintos procesos como pueden ser de defensa de la tierra, de la cultura $y / o$ de los derechos ancestrales; de resistencias políticas, conflictos externos como la guerra, etc., y su manifestación y desarrollo obedece a formas tradicionales de organización social y a los elementos que es preciso innovar para responder a los cambios que buscan altemativas de solución a los problemas cotidianos. Los resultados obtenidos han permitido definir dos líneas de líneas de trabajo:

- Ampliar la comprensión científica de la relación conflicto-identidadsociedad, así como sus distintas manifestaciones, en el Macizo Colombiano, para avanzaren la construcción de una teoría del conflic to en Colombia. Resultado que debe obtenerse de la interacción de todos los proyectos del Programa de Historia Local y Regional.

3. Decimos sistenático en la medida on que cubre todo el territorio ded Macizo Colombiano, zona indigena y campesina los estudios previos. Romoli (1962) y Friede (1944) se restringieron a lo histórico; el de Faust (1990) presenta una mirada, si bien cinoligica, perr que se restringe a Rioblanco. 
- Fortalecer en las comunidades los mecanismos de participación, formas de apropiación y canales de reproducción y creación de sentido de los resultados del proceso de investigación, que propendan por la definición de imaginarios sociales con proyección política.

Los resultados del año 1993, previos al documento final, se pueden evaluar en los artículos presentados por los miembros del equipo de investigación en foros académicos: "Identidad étnica: ¿Proyecto de sociedad o cultura de la intolerancia?" de Diana Rocio Rojas Florez; "Autonomía y Comunidad” de Elizabeth Castillo; "Imagenes religiosas, identidad y cohesión social” de Jorge Alberto Hormiga (+); "Reapropiaciones simbólicas de tradiciones de la identidad de los yanaconas" de Claudia Leonor López; y "Cultura y Etnicidad entre los yanacona del Macizo Colombiano", "Procesos étnicos y cambio global en el Suroccidente Colombiano", e "Iconos, mitos y etnicidad" de Carlos Vladimir Zambrano. La mayoría de los anteriores fueron presentados al XIII Congreso Internacional de Ciencias Antropológicas y Etnológicas celebrado en México.

En relación con la segunda línea de trabajo, los miembros del Proyecto, delegados por los cabildos, se constituyeron en un grupo asesor del Cabildo Mayor del Pueblo Yanacona, órgano de gobierno indígena en el Macizo. Laureano Hoyos, Emiro Chicangana, Luis Olmos Chicangana, Parmenides Ruales, Greófores Anacona y Maritza Piamba, han extendido la labor del Equipo a las veredas de sus resguardos y comunidades y están buscando recursos para sacar adelante, bajo la coordinación de Elizabeth Castillo Guzmán, asesora pedagógica del proyecto, los textos sobre pensamiento político yanacona y los niños y la educación yanacona.

\section{BIBLIOGRAFIA}

FAUST, Franz.

1990 Etnogeografía y etnogeología de Coconuco y Sotará. Revista Colombiana de Antropología, Vol. XXVII, Bogotá.

FRIEDE, Juan.

1944

El indio en la lucha por la tierra. Editorial Espiral. Bogotá.

ROMOLI, Kathleen

1962 El suroeste caucano y sus ind ios al tiempo de la conquista de los españoles, según documentos contemporáneos de Distrito de 
Almaguer. Revista Colombiana de Antropología, Vol. XI, Bogotá.

\section{ZAMBRANO, Carlos Vladimir}

1993 Hombres de páramo y montaña. Los yanaconas del Macizo Colombiano. Instituto Colombiano de Antropología-Plan Nacional de Rehabilitación. Programa de Historia Local y Regional. Bogotá. 